\title{
Investigating the Characteristics, Evolution and Restoration Modes of Mining Area Ecosystems
}

\author{
Jihong Dong*, Lingran Meng, Zhengfu Bian, Aman Fang \\ School of Environmental Science and Spatial Informatics, China University of Mining and Technology, \\ Xuzhou, China
}

Received: 16 May 2018

Accepted: 8 October 2018

\begin{abstract}
The exploitation and utilization of mineral resources bring changes of the regional material cycle and energy flow, resulting in degradation and negative evolution of the local ecosystem. Many countries are committed to researching ecological environment issues and have proposed a series of techniques and methods in recent years, but the comprehensive study of mining area ecosystems and restoration modes is not enough. To further clarify the mining area ecosystem and global restoration, this research analyzed the characteristics and functions of the ecosystem in mining areas, explored its evolution principles, types and processes, and put forward four typical ecological restoration modes. The mining area ecosystem features open, artificial and complex characteristics and special energy and material flows. Its functions mainly refer to the input and output of materials, energy, information and stream of people in the internal and external systems. The ecosystem evolution of mining areas consists of negative evolution and positive evolution in arid and semi-arid areas and humid and semi-humid areas. Overall, four typical restoration modes of mining area ecosystems are featured, including land engineering reclamation, soil improvement and vegetation restoration, secondary wetland construction and ecological self-restoration modes.
\end{abstract}

Keywords: mining area ecosystem; ecosystem function; evolution principle; evolution type; restoration mode

\section{Introduction}

Mining is an important pillar industry to the economic future of many countries, and the mineral resources will be exploited largely and continuously with the growth of economic development for energy

*e-mail: dongjihong@cumt.edu.cn demand [1]. However, the exploitation and utilization of mineral resources will inevitably change the material cycle and energy flows of a regional ecosystem, break the balance of the original ecosystem, and bring a series of eco-environmental problems such as surface subsidence, groundwater penetration, soil pollution and biodiversity reduction [2-4]. The composition, structure and functionality of the mining area ecosystem can be seriously damaged and its stability can be lost, leading to reverse evolution of the original ecosystem. Negative 
ecological effects will then become increasingly prominent and the sustainable development and management in mining areas will become a concern $[5,6]$. Thus, the restoration of mining area ecosystems is crucial.

Researchers have paid more attention to the ecological damage caused by the evolution of mining area ecosystems and the exploitation and utilization of mineral resources [7-9]. At present, research of mining area ecology is mainly focused on ecosystem health and risk assessment, value estimation of ecosystem services, impact assessment of ecosystem restoration and pollution [10-15]. In the succession of mining area ecosystems, studies are predominantly concentrated on the local succession of the mining land, vegetation or landscape pattern [16-18], especially in the remediation effects of soil remediation techniques or measures adopted in the local succession process [19, 20]. For ecological restoration in mining areas, studies on contaminated site rehabilitation, environmental pollution control and the improvement of ecological benefits using state of the art technologies and advanced methods are more extensive. This includes, for example, transgenic plants in environmental clean-up, nano-enhanced materials and microorganisms for reclamation of mine lands [21-23]. However, most studies neglected the integrity of the ecosystem and ecological process of mining areas, and the research on the influence and law of mining activities on the evolution of mining area ecosystems from a long-term, dynamic view is very limited.

This paper, based on the analysis of the structure, characteristics and functionalities of a mining area ecosystem, explores evolution principles of the mining area ecosystem, summarizes the evolution types and processes, and proposes four ecological restoration modes, including land engineering reclamation, soil improvement and vegetation restoration, secondary wetland construction and ecological self-recovery according to the different geographical conditions and types of damaged sites in mining areas of the world's major mining countries. This paper is intended to provide a new synthesis of the mining area ecosystem through a comprehensive analysis of global mining ecology, which is a summary and extension of ecological theory of the mining area. This paper also provides a theoretical and technical reference for ecological management in mining areas. The results are of great significance for maintaining the stability and promoting the healthy development of the mining area ecosystems.

\section{Characteristics and Functions of Mining Area Ecosystems}

A mining area refers to the production and utilization areas of mineral resources and workers' living quarters (as the core areas) and the economic and administrative areas involved. The overall mining area includes a complete production process, ground transportation, power supply, telecommunication scheduling, production management, life services and other facilities, which can be divided into openpit mining and underground mining areas. China has abundant coal resources and almost all types of coals, and it is characterized with the regional distribution

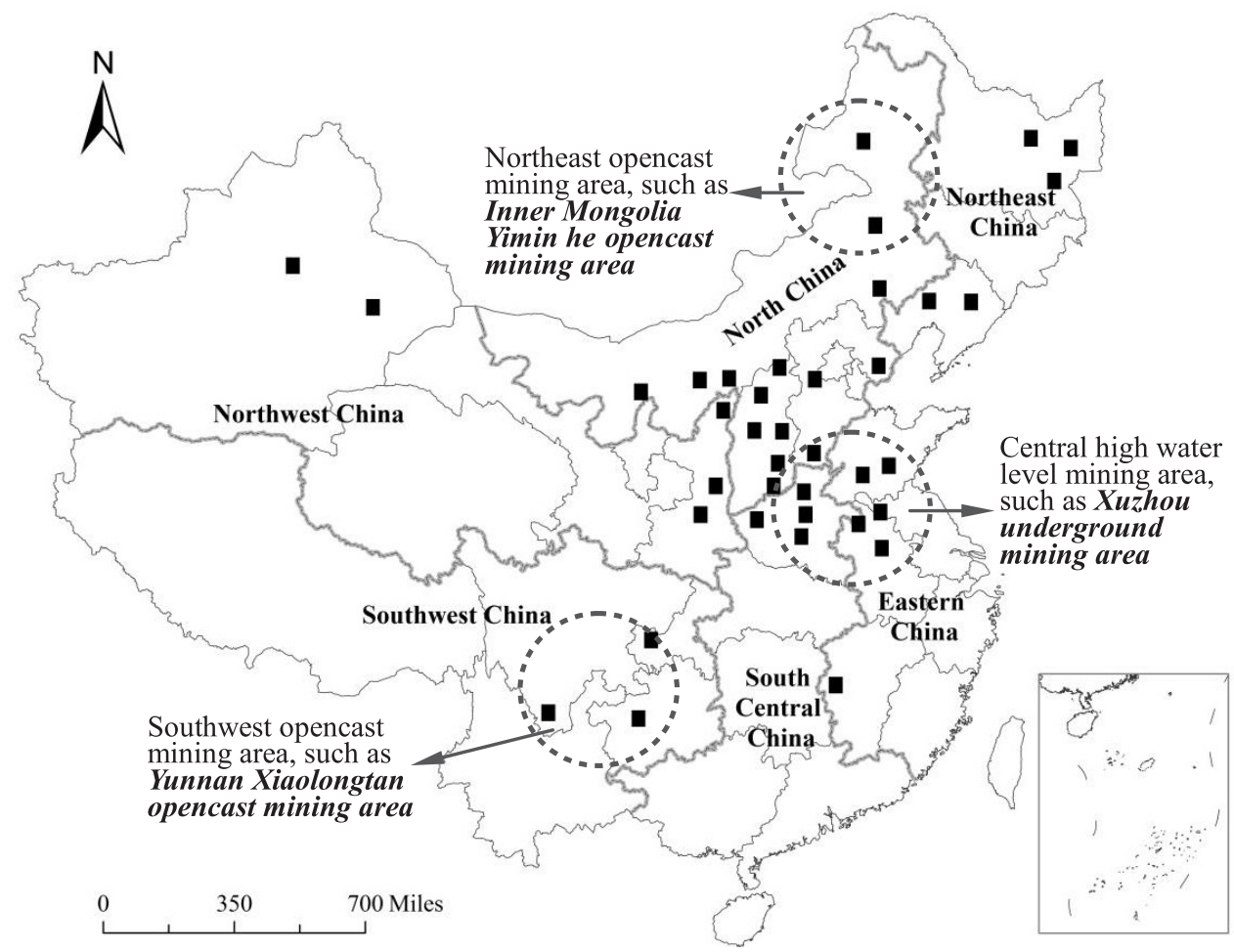

Fig. 1. Main distribution of mining areas in China. 
pattern of "west more and east less, north rich and south poor." The mining areas in China are widely distributed, and the typical mining areas include northeast opencast mining, central high water level mining and southwest opencast mining (Fig. 1). The mining area ecosystem can be considered as a kind of "social-economicnatural" composite ecosystem established on the basis of the transformation and adaptation to the natural environment. It is mainly dominated by the exploitation and utilization of mineral resources. It is also a complex system formed by the interaction of the residents, the natural-environmental system and the socialenvironmental system established by humans in the space of the mining area $[4,24,25]$.

\section{Structure of Mining Area Ecosystems}

As a typical complex ecosystem, the mining area ecosystem is a multi-level, multi-functional and complex dynamic system that refers to the interaction and restriction among humans (mining workers, local residents, etc.), the corresponding natural-environmental system (atmosphere, water, plants, animals, soil, rocks, etc.) and the spatial social-economic-environmental system in the mining area through energy flows, material flows and information flows, and forms a compound ecosystem based on the exploitation and utilization of mineral resources. Humans act as a "coupler" in the ecosystem, and the three subsystems are finally coupled to form a complex ecosystem in the mining area [26].

The mining area ecosystem can be divided into natural subsystem, social subsystem and economic subsystem. The natural subsystem is the foundation of the social and economic subsystems, mainly including non-biological systems (atmosphere, hydrology, land, etc.), resource systems (mineral resources and solar, wind, water, etc.), the biological system of wild animals and plants, microorganisms and artificial cultivation of biological populations. The social subsystem of the mining area is centered on the mine residents, including the relevant environment to meet their needs of production, life, education and medical care, and the consumption system that inputs the material and energy flow to the economic subsystem at the same time. The economic subsystem includes all the available material and energy in mining area compound ecosystem (service industry, agriculture and mining), and is the whole process of mineral resource production to meet the social-economic system demand [16].

\section{Characteristics of Mining Area Ecosystems}

The mining area ecosystem is an ecosystem that changes the original system structure, material circulation and energy conversion, and is affected by human production and life. It has the characteristics of a general natural ecosystem, namely the relationship between the biological community and surrounding environment, as well as the ability of material circulation, energy flow and self-regulation. Meanwhile, due to the constraints of social productivity and production relations, the self-regulating ability of mining area ecosystem is weakened $[27,28]$. The mining area ecosystem generally has the following characteristics.

- Open: The mining area ecosystem is an opening system closely related to the "natural-economicsocial" composite system of the whole society. Therefore, the ecosystem is dominated by the laws of natural-ecological, as well as social-economic laws.

- Artificial: The mining area ecosystem is a humancentered ecosystem, and its production, existence, development and extinction are carried out according to human wishes.

- Complex: The mining area ecosystem is a kind of "social-economic-natural" composite ecosystem, which is dominated by the exploitation and utilization of mineral resources.

- Special energy and material flows: The mining area ecosystem has special energy and material flows, mainly manifested as the energy and material flows being open. Energy flow transmits energy mainly through the human-controlled material flows, such as mining, washing, transportation, energy conversion and material reuse, which is mainly regulated by artificial information flow, and needs a large amount of auxiliary energy and materials.

\section{Functions of Mining Area Ecosystems}

The functions of mining area ecosystems refer to the function of the system and its internal subsystems or components. A mining area ecosystem is an open human ecosystem. According to the material, energy, information exchange direction and scope of the system, the functions of a mining area ecosystem can be divided into external and internal functions (Fig. 2).

The external function refers to the effect of a mining area ecosystem on other systems. According to the

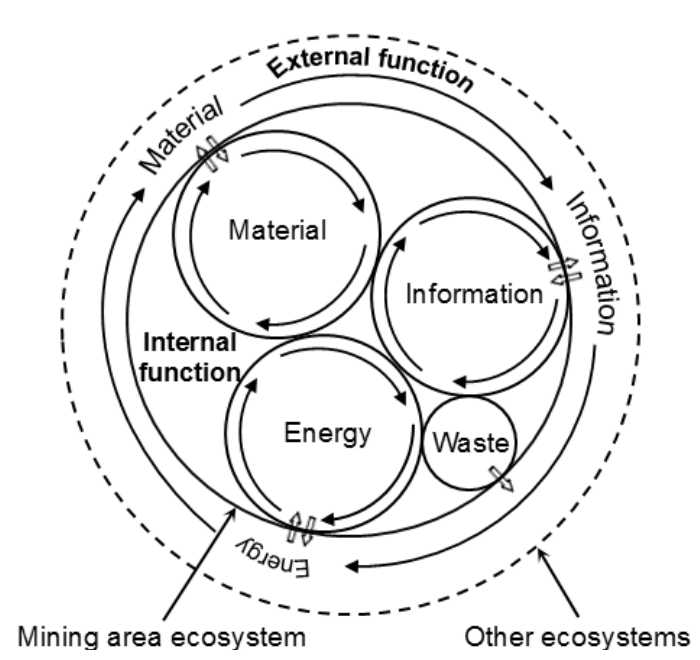

Fig. 2. The exchange of energy, material and information flow in mining area ecosystems. 
internal demand of the system, the material, energy and information exchange are continuously exchanged with the external system to ensure the normal operation and balance of energy flow and material circulation. Internal function refers to the interaction among the subsystems of the mining area ecosystem, mainly to maintain the circulation and smoothness of energy, information and material flow in an internal system, and forms a variety of feedback mechanisms to regulate the external functions to output redundant or unnecessary material, energy to other ecosystems. The external function of mining area ecosystems need to be completed by the coordination of internal function. Therefore, the function of mining area ecosystems mainly performs as input and output of the material, energy, information and people stream in internal and external systems.

\section{Evolution of Mining Area Ecosystems}

The evolution of mining area ecosystems refers to the sequential process in which the original ecosystem is disturbed and replaced by another ecosystem with the passage of time and the development of mineral resource exploitation activities. In accordance with the order of time development, the mining area ecosystem has experienced three stages of primitive, predatory and coordinated [27]. The evolution of a mining area ecosystem is closely related to the location, natural climate conditions, mining methods and human production activities. Different conditions make the evolution types and processes of mining area ecosystem different.

\section{Evolution Principle}

The evolution of the mining area ecosystem is closely related to the exploitation and utilization of mineral resources. Large-scale exploitation and utilization of mineral resources play an important role in driving the economic development of the mining area and its surrounding areas. However, problems such as depletion of mineral resources, environmental pollution, single pillar industry and other issues have a negative effect on the development of the regional economy. According to the formation and development of the mining area ecosystem, its evolution process can be divided into the formation, damage, rebuild and dynamic balance stages. The specific evolution stages of a mining area ecosystem are shown in Fig. 3.

In the formation stage of a mining area ecosystem, energy and material flows are gradually formed, the relevant production factors are basically completed, and the original ecosystem is less disturbed by the outside and has higher stability. In the damaged stage, a large amount of arable land, woodland, etc. has been converted into industrial and mining land with the development

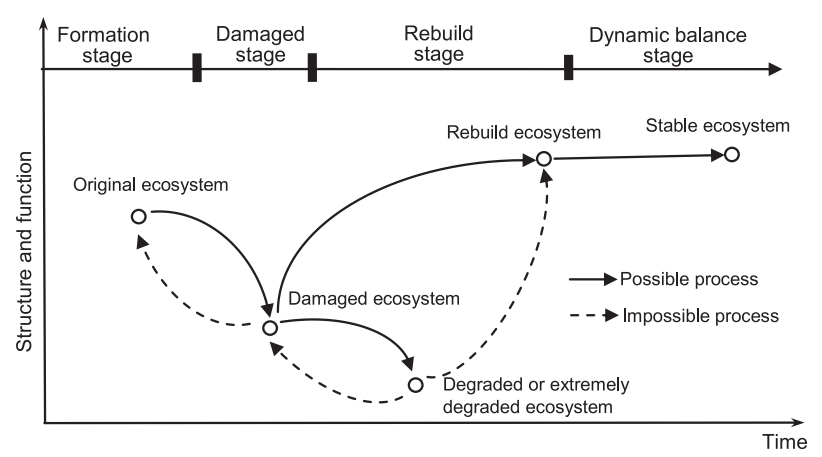

Fig. 3. Evolution stages of typical mining area ecosystems.

of mineral exploitation, the original ecosystem has been damaged and degraded (or extremely degraded), resulting in a series of ecological environmental problems such as soil pollution, surface subsidence and air pollution. In the rebuild stage, the mining industry loses its dominant position of the regional economy with the gradual depletion of mineral resources, and the damaged ecosystem will be rebuilt under artificial restoration measures and self-repair conditions, such as land reclamation, pollution removal and vegetation restoration. Finally, the original ecosystem is destroyed and evolves into a new dynamic and stable ecosystem. However, this evolution process is irreversible, and the damaged or degraded ecosystem back to the original ecosystem is an impossible process.

\section{Evolution Type}

The mining area ecosystem can be divided into arid and semi-arid areas and humid and semi-humid areas, according to the geographical location and climatic condition of the mining area. The evolution direction of mining area ecosystems mainly depends on the type of pre-mining ecosystems, location and climatic conditions of mining areas. The types of pre-mining ecosystems can be generally divided into natural ecosystems and artificial ecosystems. The natural ecosystems include aquatic and terrestrial ecosystems, and the artificial ecosystems include farmland, urban, etc.

The mining areas of arid and semi-arid areas see a shortage of water resource, and the ecosystem is extremely fragile. The exploitation of mineral resources is easy to cause soil erosion and land desertification, and the original mining area ecosystem (grass land, desert and semi-desert, etc.) generally evolves to the extreme desertification or severe desertification ecosystem. However, the mining areas in humid and semi-humid areas generally have flat terrain and high underground water levels, the mining subsidence water will change the original terrestrial ecosystem (farmland, woodland, grass land and residential land, etc.) and make it evolve into aquatic or land and water symbiosis ecosystem (Fig. 4). 


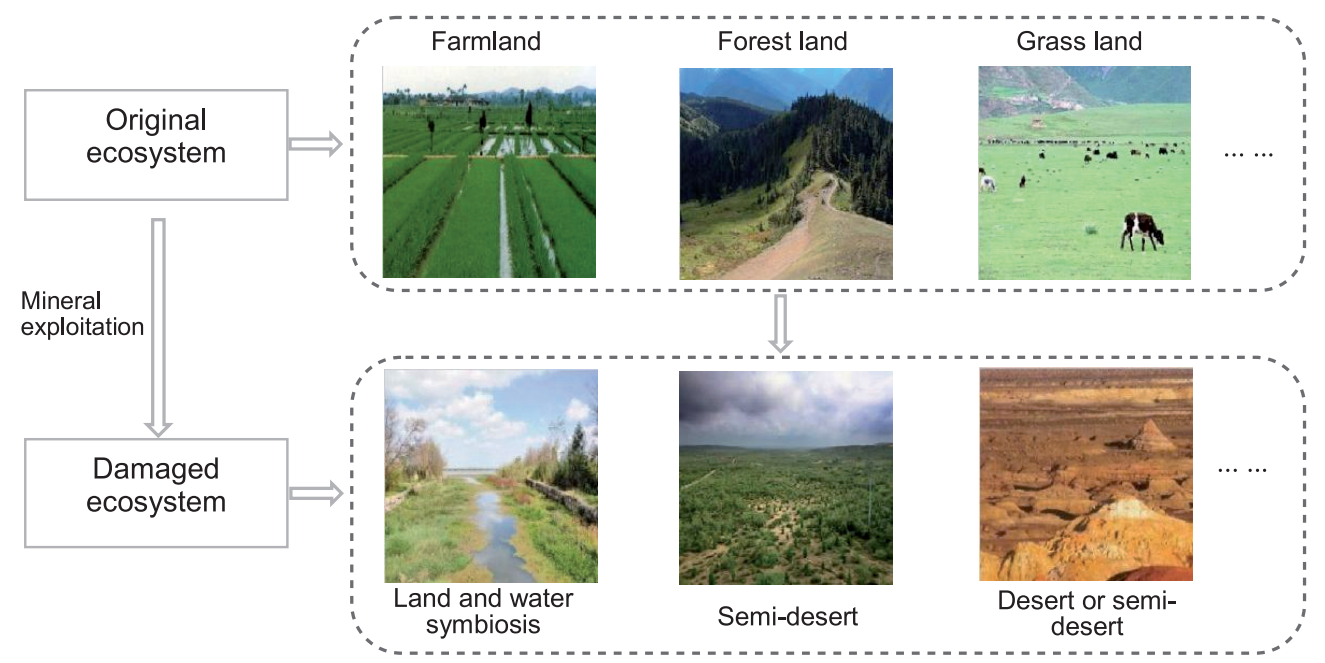

Fig. 4. Evolution types of typical mining area ecosystems.

\section{Evolution Process}

Due to the impact of mining activities, the original ecosystem was damaged by severe human destructive interference, resulting in the negative evolution of the ecosystem and finally evolving to extreme degradation. The ecological restoration of a mining area is a kind of gain disturbance to the mining area damaged ecosystem, which makes the damaged ecosystem carry out positive evolution under the dual effects of human disturbance and natural restoration through proper engineering and biological measures, and then reaches the acceptable state of humans. The evolution process of mining area ecosystems is shown in Fig. 5. The mining area ecosystem forms a degraded ecosystem and even extremely degraded ecosystem after negative evolution, while an ideal ecosystem after positive evolution. The positive evolution is the process of the mining area ecosystem evolving in the direction of human expectation through the interaction between human transformation and natural evolution, including the restoration and reconstruction of land, hydrological, vegetation, landscape, etc.

\section{Restoration Modes of Mining Area Ecosystems}

For the restoration of a mining area ecosystem, different techniques and methods are adopted according to the characteristics of the object, the target and the specific function after restoration. Also, the restoration modes of mining area ecosystems in global mining countries are different because of different geographical locations, climate conditions and evolution directions. The early restoration mode in Germany was mainly based on forestry and agricultural reclamation, and gradually transformed into a compound restoration mode of tourism and leisure, and species protection; America and Australia mainly carried out landform remodeling and vegetation restoration by land reclamation; in addition, it also include the garden restoration mode in British and Canada, and wetland park, strait park modes

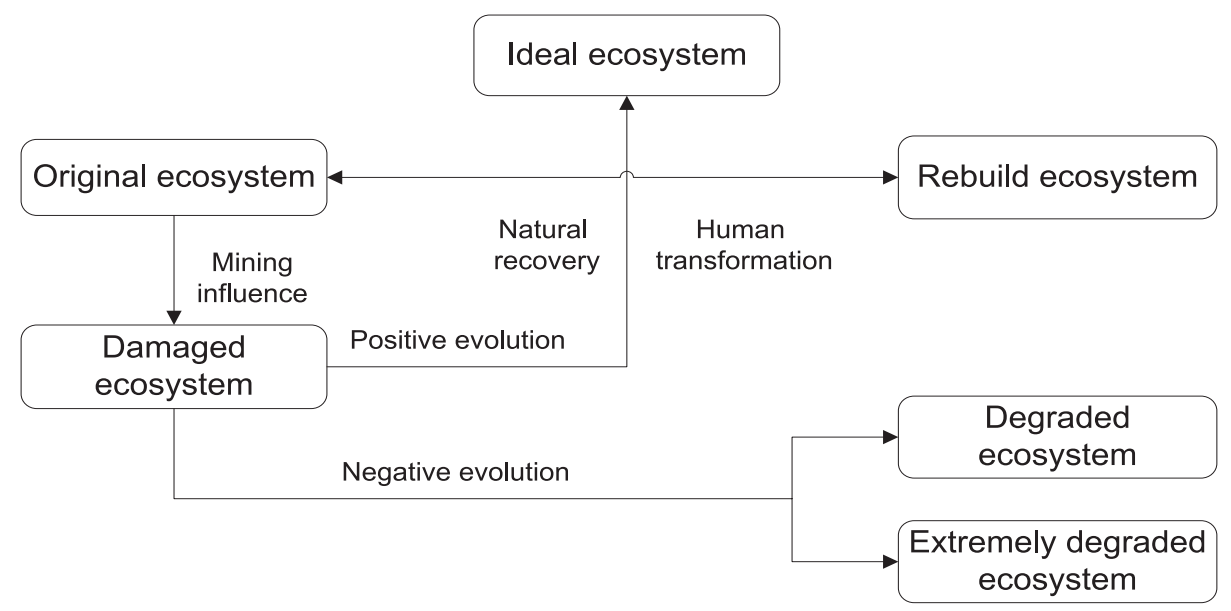

Fig. 5. Evolution process of typical mining area ecosystems. 
in South Africa and Japan [29-31]. In China, the practice of ecological restoration in mining areas is relatively late, mainly referring to the advanced models of developed countries such as Germany and Australia, and constantly improving according to the requirements of mining area reclamation. In summary, combined with the reality of mining restoration in global major mining countries, the restoration modes of mining area ecosystems mainly include land engineering reclamation, soil improvement and vegetation restoration, construction secondary wetland, and ecological self-restoration.

\section{Land Damage in Mining Areas: Land Engineering Reclamation Mode}

Land engineering reclamation refers to backfilling, leveling, overburdening and comprehensive remediation to the sequential backfilling, leveling, covering and comprehensive renovation of damaged land in combination with the characteristics of mining engineering [32]. Its core is reclaiming land, and forms a new ecological community and ecological environment. The land reclamation technics in a mining area are shown in Fig. 6.

- Topsoil stripping reclamation refers to taking the mining production and land reclamation requirements into consideration in the preparation of a mining plan, and planning mining and stripping operations and land reclamation operations as a whole. The topsoil stripped from the open pit can be devoted to land reclamation in-situ or off-site, soil improvement, reclamation, and other uses. The stripped topsoil is generally fertile, it can reduce the soil maturation time and capital investment of the transferred soil effectively during reclamation, and is one of the effective ways of mining area ecosystem restoration. For topsoil stripping reclamation, firstly, calculating the earthwork of each scraper in the width range from outside to inside (the subsidence center) according to the width of the scraper. Secondly, divide the land reclamation areas into different reclamation bands and borrow areas, and each band is approximately the integer times of the width of the scraper. Finally, strip layer upon layer from outside to inside.

- Land reclamation in spoil bank is mainly divided into four steps: from the dumping process to the available state after reclamation, namely basement construction, subject construction, platform construction and slope construction of the spoil bank. The early stage of piling up rock-soil in spoil bank is basement construction, and good basement construction is conducive to the overall stability of the spoil bank. Soft base clearance technology, smooth substrate blasting treatment technology and anti-sliding technology can be adopted to enhance the bearing capacity of the basement rock, improve the anti-sliding ability of the spoil bank and control the slide of rock-soil in the inclined base. Subject construction of the spoil bank mainly includes discharging multi-point waste synchronously, controlling the sequence of discharging the rocksoil and discharging mixed rock-soil, which can extend the sedimentation compression process and time of the waste of the spoil bank in various areas, and reduce the later uneven settlement in the later stage. Platform construction refers to reconstructing

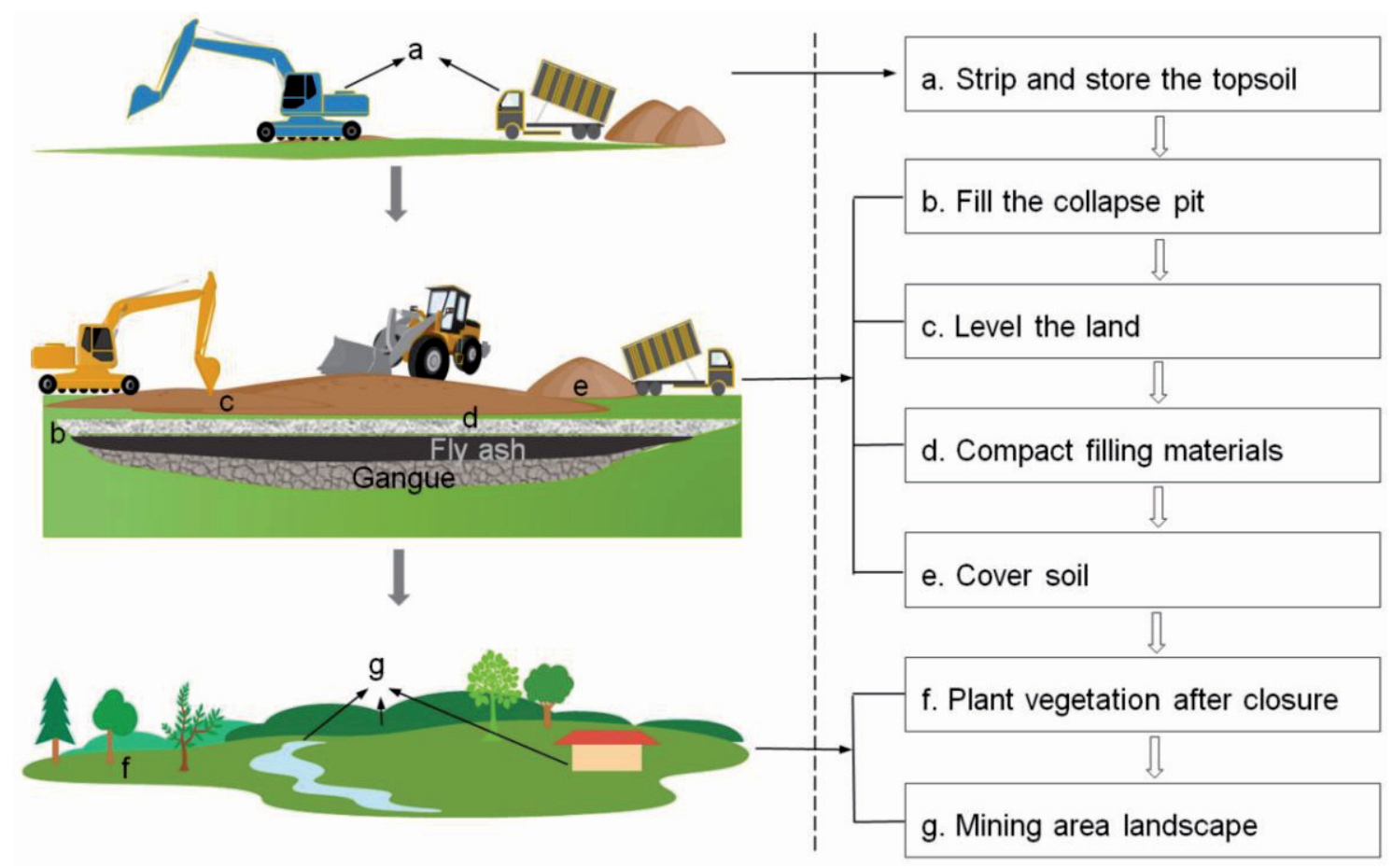

Fig. 6. Land reclamation technics in a typical mining area. 
the soil artificially to form the reclaimed planting layer. The integrated reclamation mode of "miningtransportation-disposal" and land leveling, compacting and crack treatment are adopted to reclaim the platform into available land such as forest land, grassland and cultivated land. The protective measures of multi-level steps and fish scale pits can be used in slope construction. Water-retaining walls can be built on the edge of the high-level sidestep to intercept the runoff; suitable grass and trees can be planted on the slope; and big rocks can be piled on the low-level sidestep to stem the sediment on the slope and prevent it from entering the drains on the low-level sidestep to prevent soil erosion.

- Filling reclamation in subsidence land generally includes gangue-filling reclamation, fly ash-filling reclamation and underground-filling reclamation. Gangue is waste rock produced in the process of coal mining and washing, and the gangue backfill method is mainly determined by the purpose of the backfill land and the types of gangue. The burning gangue is usually used for agriculture and forestryfilling reclamation, while the non-burning gangue is used for building land-filling reclamation. The filling methods mainly include the full thickness filling method (farmland reclamation), and filling and compaction layer upon layer method (building land reclamation). Fly ash can change soil texture, increase soil $\mathrm{pH}$, improve soil fertility and waterholding capacity, and not cause pollution to the environment and food chain, which can be used as fertilizer and conditioner to improve the reclamation of dry lands. Underground filling reclamation means filling underground directly with filling material to reduce or avoid ground subsidence, which is the prevention measure of land reclamation. The filling materials can be solid waste (coal gangue and fly ash), cement, sand, and mud, etc.

- Terrace reclamation, dredging and draining reclamation, deep-digging and shallow-filling reclamation are mainly adopted in land-leveling in mining areas. Terrace design is based on the terrain and geological conditions after the collapse, and the framing requirements to determine the section elements and leveling the subsidence land along with the contour line, and transforming the subsidence land into horizontal terrace of circular wide strip or terrace green belt. The reclamation method is generally suitable for the subsidence area with lower groundwater level, and slope zone of the water subsidence area and so on. The dredging and draining method is an effective way to solve subsidence water accumulation with high underground water levels in mining areas, which drains the water in subsidence area through excavating a large number of drainage channels to discharge subsidence water into nearby rivers, lakes and pumping stations, and carrying out the necessary renovation engineering to make mining subsidence no longer accumulate water and be restored. For deep-digging and shallow-filling reclamation, the combination of land reclamation and excavation pond, and digging the subsidence water area deeply, which sinks larger and forming ponds for farming fish, reservoirs, cisterns, or water parks. Using the dirt that dug out to fill the subsidence area which sinks lower up to the natural elevation and leveling properly to use for cultivated land or other lands. The method realizes the goal of simultaneous development of aquiculture and agricultural cultivation, with the characteristics of simple operation, wide application and high economic and ecological benefits. It is generally applicable to deep subsidence, local or seasonal water accumulation in high and medium groundwater level areas.

- Waste dump reclamation is the measure to reduce pollution of the gangue stacking to the environment in order to achieve the purpose of recovering the ecological balance and productivity of the waste dump by shaping, basal improvement and vegetation restoration. Waste dump reclamation generally includes two methods: removing the waste dump and transporting the gangue to the collapse pit or low-lying land as reclaimed materials, and reshaping the waste dump. Most of the waste dumps are coneshaped; in order to prevent erosion and runoff caused by wind and precipitation, the waste dump can be modified by pushing the soil preparation, slowing down the slope and covering the soil. According to the geometry of the waste dump after shaping, the plastic forms of the waste dump can be divided into terrace type, spiral type and micro-sidestep type. And chemical and biological methods can be used to improve the soil fertility in the waste dump, and create conditions for plant growth in order to achieve the purpose of eliminating harm, beautifying the environment and even obtaining certain economic benefits.

\section{Water Loss and Soil Erosion in Arid and Semiarid Mining Areas: Soil Improvement and Vegetation Restoration Mode}

Soil is the stromal and biological carrier of a mining area ecosystem. In arid and semiarid mining areas, soil physical and chemical properties are poor and soil erosion is serious, the natural landscape, water environment, land resources and biological communities are severely damaged, and human survival and socialeconomic development are seriously affected [33]. What's worse, soil fertility decreases, curing degree is lower, and water storage capacity and structure are poor in arid and semiarid mining areas after exploitation, which affects the metabolism of plants [34]. Therefore, it is necessary to improve the physical and chemical properties of soil factors that are not conducive to plant growth, and the general improvement methods include covering soil, adding rice husk, lime, fly ash, organic fertilizer, inoculating with mycorrhizal 
fungi, applying inorganic or organic additives, etc., which improve soil structure, increase soil fertility and water-holding capacity, and prevent soil erosion [35-37]. Under the premise of the soil system restoration in the abandoned land, the plant community can be rebuilt and the ecosystem can be gradually restored [38].

Vegetation restoration in mining areas is to control soil erosion, accelerate soil cultivation, stabilize soil structure, and form a self-regulating healthy ecosystem as soon as possible. The vegetation restoration technologies mainly include plant species selection and vegetation allocation.

- Plant species selection: according to the local climate and soil environment, selecting the plant species with strong tolerance, small water consumption, good water conservation benefits, and short growth cycle initially, then determining them by combining the methods of simulated cultivation in the laboratory, field planting, experience analogy and so on. The selection principles include using native plants with specific tolerance characteristics as the pioneer plants for vegetation construction in mining areas, or introducing alien fast-growing plants. Gramineous herbs have characteristics of simple sowing, high germination rate, rapid growth and good stress resistance in seeding stage, and forming vegetation cover rapidly after sowing, which can be used as the main plant species in the vegetation restoration of a mining area. Legume plants have nitrogen fixation ability, which can improve the soil quality of the barren mining area and promote the growth of the subsequent plants. The shrubs and trees (dungarunga) have a long life cycle and huge root system, can effectively protect the mining environment long-term after planting and be used as the main species for vegetation restoration in mining areas [39].

- The principles of vegetation allocation include adapting to local conditions, matching sites with trees, and arbor-shrub-grass stereo configuration, and the stability of biodiversity in the whole mining area ecosystem. The vegetation allocation modes in different mining area sites are different. For example, vegetation allocation modes of platform in spoil bank, first of all, improving soil fertility by planting green manure crops; after green manure crops degradation, replanting shrub and herbaceous plant to further improve the soil fertility level; and planting corps and cash corps when soil indicators reach high-quality arable land levels. For vegetation allocation modes of side slope in spoil bank, stereo planting structure of shrub and herbaceous plant should be adopted, which can play the role of wind and sand fixation. For vegetation allocation modes of surrounding areas in the spoil bank, protective forest should be set up to beautify the environment and prevent wind and sand fixation.

\section{Subsidence Pit Water in Mining Areas with High Underground Water Level: Construction Secondary Wetland Mode}

The high groundwater level mining area has the characteristics of flat terrain, low buried depth, large recoverable coal seam, large thickness of coal seam and large subsidence coefficient of ground surface. Mining activities will cause surface damage, ground collapse and the destruction of the original drainage system, the collection of atmospheric precipitation, underground water and surface runoff cannot be discharged, and it accumulates in the low-lying areas, forming a small area of sporadic waters or contiguous concentrated waters. According to the condition of water accumulation, the secondary wetland in the mining area can be divided into permanent water accumulation and seasonal water accumulation wetland, and the terrestrial ecosystem gradually evolves into an aquatic ecosystem. The formation of secondary wetland in a mining area is shown in Fig. 7.

Different remediation measures can be taken according to the size of the water accumulation area and
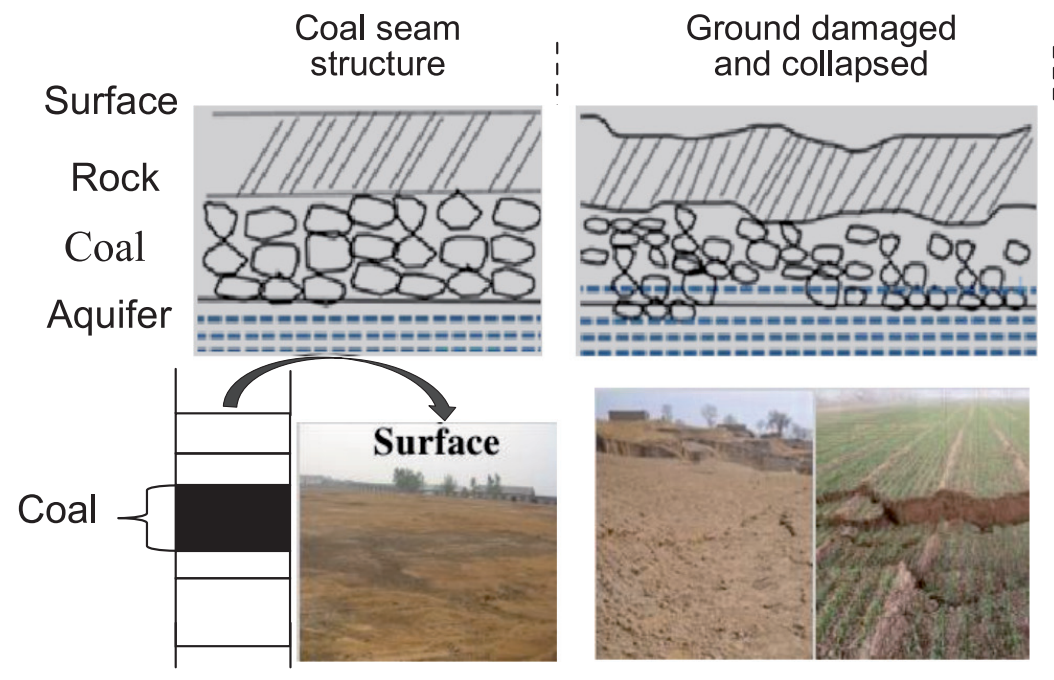

Formation of sporadic and contiguous water formed



Fig. 7. Formation of secondary wetland in a typical mining area. 
the water level [40]. Dredging and draining reclamation can be taken in the area with shallow water collapse pit to drain water by establishing a drainage system. Deep-digging and shallow-filling reclamation can be taken in the area with various-depth water collapse pit, continuing to dig deeper the deep subsidence areas and filling the shallow subsidence areas with the dirt dug out for restoration into fish ponds and arable land respectively to realize land reuse. A three-dimensional ecological development mode can be taken in the perennial water area, and reconstruct the subsidence water area into comprehensive land for aquiculture and tourism.

\section{Local "Non-Overload" of Original Ecosystem: Ecological Self-Restoration Mode}

Self-restoration is the method relying on natural forces to restore an ecosystem, and natural forces refer to the various biological, chemical and physical functions existing in nature [41, 42], such as climate change, soil natural seed bank, seed natural propagation, and natural characteristics of soil and plants.

The ecological self-restoration of a mining area is to make the damaged mining area ecosystem gradually restored to the ecosystem with higher levels relying on natural effects without any human disturbance. In the condition that the original ecosystem is far from being "overloaded," the ecosystem can be self-purifying and may realize self-restoration over time. However, the exploitation and utilization of mineral resources usually leads to extreme degradation and "overloads" the operation of a mining area ecosystem, and it is impossible to realize self-restoration of the whole mining area ecosystem relying only on the self-purification ability, but the local ecological self-restoration in a mining area is possible, such as the self-restoration of water and plants.

\section{Conclusions}

The mining area ecosystem is a "natural-socialeconomic" complex dynamic system dominated by the exploitation of mineral resources and human activities. In this paper, the integrity of the ecosystem and ecological process are analyzed from the perspective of characteristics and functions, evolution types and processes, and restoration modes in mining areas. The evolution framework and restoration modes of the mining area ecosystem can provide theoretical and technical support for the development and management of mining areas.

The mining area ecosystem is open, artificial and complex, and special energy and material flows. Its functions can be divided into external function and internal function, and mainly refer to the input and output of materials, energy, information and people stream in the internal and external systems to ensure the circulation and stability of the whole ecosystem. The evolution direction of the mining area ecosystem is mainly determined by the type of pre-mining ecosystem, locations and climatic conditions of a mining area. The evolution types include "terrestrial ecosystem to terrestrial ecosystem" in arid and semi-arid areas and "terrestrial ecosystem to aquatic or land and water symbiosis ecosystem" in humid and semi-humid areas. Four restoration modes of mining area ecosystem are proposed, including land engineering reclamation mode, soil improvement and vegetation restoration mode, construction secondary wetland mode, and ecological self-restoration mode according to different ecological problems.

The evolution of mining area ecosystems consists of negative evolution and positive evolution. The mining area ecosystem forms a degraded ecosystem and even extremely degraded ecosystem after negative evolution, while ideal ecosystems after positive evolution. The objective of our study was to grasp the evolution characteristics, laws and patterns, and to seek effective technical measures and methods for the positive evolution of the mining area ecosystem, as well as promoting land reclamation and restoration practice in mining area to improve the stability and sustainability of mining area ecosystems.

\section{Acknowledgements}

This research was financially supported by the Fundamental Research Funds for the Central Universities (No. 2014ZDPY30), for which we are very grateful. We also express our thanks to the reviewers for their innovative and supportive comments.

\section{Conflict of Interest}

The authors declare no conflict of interest.

\section{References}

1. RANOSZ R. Mining and its role in the global economy. Gospodarka Surowcami Mineralnymi - Mineral Resources Management. 30 (1), 5, 2014.

2. MBAYA R.P. Land Degradation Due To Mining: the Gunda Scenario. International Journal of Geography and Geology, 2 (12), 144, 2013.

3. DONG J.H., YU M., BIAN Z.F., WANG Y., DI C.L. Geostatistical analyses of heavy metal distribution in reclaimed mine land in Xuzhou, China. Environmental Earth Sciences, 62 (1), 127, 2011.

4. ZHANG J.X., ZHANG Q., SUN Q., GAO R., GERMAIN D., ABRO S. Surface subsidence control theory and application to backfill coal mining technology. Environmental Earth Sciences, 74 (2), 1439, 2015.

5. YANG Y.J., ZHANG S.L., HOU H.P., XIAO-SHUN L.I. The Ecological Impacts of Coal Mining and the Regional Differentiation. China Land Sciences, 29 (1), 55, 2015. 
6. CEJPEK J., KURÁŽ V., FROUZ J. Hydrological properties of soils in reclaimed and unreclaimed sites after brown-coal mining. Polish Journal of Environmental Studies, 22 (3), 645, 2013.

7. DRUMMOND M.A., AUCH R.F., KARSTENSEN K.A., SAYLER K.L., TAYLOR J.L., LOVELAND T.R. Land change variability and human-environment dynamics in the United States Great Plains. Land Use Policy, 29 (3), 710, 2012.

8. ALEMAYEHU F., TAHA N., NYSSEN J., GIRMA A., ZENEBE A., BEHAILU M., POESEN J. The impacts of watershed management on land use and land cover dynamics in Eastern Tigray (Ethiopia). Resources, Conservation and Recycling, 53 (4), 192, 2009.

9. LEI K., PAN H.Y., LIN C.Y. A landscape approach towards ecological restoration and sustainable development of mining areas. Ecological Engineering, 90, 320, 2016.

10. FENGLER F.H., BRESSANE A., CARVALHO M.M., LONGO R.M., DE MEDEIROS G.A., DE MELO W.J., RIBEIRO A.I. Forest restoration assessment in Brazilian Amazonia: A new clustering-based methodology considering the reference ecosystem. Ecological Engineering, 108, 93, 2017.

11. DONG J., DAI W., SHAO G., XU J. Ecological Network Construction Based on Minimum Cumulative Resistance for the City of Nanjing, China. ISPRS International Journal of Geo-Information, 4 (4), 2045, 2015.

12. HOGAN D.M., LABIOSA W., PEARLSTINE L., HALLAC D., STRONG D., HEARN P., BERNKNOPF R. Estimating the cumulative ecological effect of local scale landscape changes in South Florida. Environmental Management, 49 (2), 502, 2012.

13. CZAJA S., RAHMONOV O., WACH J., GAJOS M. Ecohydrological monitoring in assessing the mining impact on riverside ecosystems. Polish Journal of Environmental Studies, 23 (2), 629, 2014.

14. SLADE E.M., KIRWAN L., BELL T., PHILIPSON C.D., LEWIS O.T., ROSLIN T. The importance of species identity and interactions for multifunctionality depends on how ecosystem functions are valued. Ecology, 98 (10), 2626, 2017

15. DUDHAGARA D.R., RAJPARA R.K., BHATT J.K., GOSAI H.B., SACHANIYA B.K., DAVE B.P. Distribution, sources and ecological risk assessment of PAHs in historically contaminated surface sediments at Bhavnagar coast, Gujarat, India. Environmental Pollution, 213, 338, 2016

16. LI B.J., GU H.H., JI Y.Z. Evaluation of landscape pattern changes and ecological effects in land reclamation project of mining area. Transactions of the Chinese Society of Agricultural Engineering, 28 (3), 251, 2012

17. RAVAL S., SHAMSODDINI A. A monitoring framework for land use around kaolin mining areas through Landsat TM images. Earth Science Informatics, 7 (3), 153, 2014.

18. STAMOU G.P., PAPATHEODOROU E.M. Studying the complexity of the secondary succession process in the soil of restored open mine lignite areas; the role of chemical template. Applied Soil Ecology, 103, 56, 2016.

19. METSLAID S., STANTURF J.A., HORDO M., KORJUS H., LAARMANN D., KIVISTE A. Growth responses of Scots pine to climatic factors on reclaimed oil shale mined land. Environmental Science and Pollution Research, 23 (14), 13637, 2016.
20. STUMPF L., PAULETTO E.A., PINTO L.F.S. Soil aggregation and root growth of perennial grasses in a constructed clay minesoil. Soil and Tillage Research, 161, 71, 2016.

21. SETH C.S. A review on mechanisms of plant tolerance and role of transgenic plants in environmental clean-up. Botanical Review, 78 (1), 32, 2012.

22. HARRIS M.A., RAGUSA S. Bacterial mitigation of pollutants in acid drainage using decomposable plant material and sludge. Environmental Geology, 40 (1-2), 195, 2000.

23. VENKATESWARLU K., NIROLA R., KUPPUSAMY S., THAVAMANI P., NAIDU R., MEGHARAJ M. Abandoned metalliferous mines: ecological impacts and potential approaches for reclamation. Reviews in Environmental Science and Biotechnology, 15 (2), 327, 2016.

24. NUSSBAUMER Y., COLE M.A., OFFLER C.E., PATRICK J.W. Identifying and ameliorating nutrient limitations to reconstructing a forest ecosystem on mined land. Restoration Ecology, 24 (2), 202, 2016.

25. DUN Y.L., WANG J., BAI Z.K., CHEN X.H., GUO Y.Q. Changes in Pingshuo opencast mining area ecosystem service values based on grey prediction modeling. Resources Science, 37 (3), 494, 2015.

26. WU J.G. Dissipative structure, hierarchy theory and ecosystems. Chinese Journal of Applied Ecology, 2 (2), 181, 1991.

27. YAN X.Q., WANG G.C. Primary discussion on mining area compound ecosystem theory. China Mining Magazine, 12 (8), 22, 2003.

28. HU Z.Q., XIAO W., FU Y.H. Introduction to Concurrent Mining and Reclamation for Coal Mines in China, 781, 2014.

29. SRIVASTAVA N.K., RAM L.C., MASTO R.E. Reclamation of overburden and lowland in coal mining area with fly ash and selective plantation: A sustainable ecological approach. Ecological Engineering, 71, 479, 2014.

30. WERNER K. Reclamation of land damaged by open-cast mining - Methods and results. Biological Conservation, 5 (4), 277, 1973.

31. QUINKENSTEIN A., FREESE D., BÖHM C., TSONKOVA P., HÜTTL R.F. Agroforestry for MineLand Reclamation in Germany: Capitalizing on Carbon Sequestration and Bioenergy Production. In P. K. R. Nair \& D. Garrity (Eds.), Agroforestry - The Future of Global Land Use (pp. 313-339). Dordrecht: Springer International Publishing, 313, 2012.

32. HU Z.Q., BIAN Z.F., HU S. Land reclamation and ecological restoration. Xuzhou: China University of Mining \& Technology Press. 2008.

33. DA SILVA G.A., TRUFEM S.F.B., JUNIOR O.J.S., MAIA L.C. Arbuscular mycorrhizal fungi in a semiarid copper mining area in Brazil. Mycorrhiza, 15 (1), 47, 2005.

34. WANG S.M., DU H.D., Analysis of damage process and mechanism for plant community and soil properties at northern Shenmu subsidence mining area. Journal of China Coal Society, 42 (1), 17, 2017.

35. FINKENBEIN P., KRETSCHMER K., KUKA K., KLOTZ S., HEILMEIER H. Soil enzyme activities as bioindicators for substrate quality in revegetation of a subtropical coal mining dump. Soil Biology and Biochemistry, 56, 87, 2013. 
36. WANG Z.G., BI Y.L., JIANG B., ZHAKYPBEK Y., PENG S.P., LIU W., LIU H. Arbuscular mycorrhizal fungi enhance soil carbon sequestration in the coalfields, northwest China. Scientific Reports, 6 (1), 34336, 2016.

37. RADZIEMSKA M. Enhanced phytostabilization of metal-contaminated soil after adding natural mineral adsorbents. Polish Journal of Environmental Studies, 27 (1), 267, 2018.

38. WANG H.D., WANG J.M., CAO Y.G., LU Y.Q., QIN Q., WANG Y. Effect of soil and topography on vegetation restoration in an opencast coal mine dump in a loess area. Acta Ecologica Sinica, 36 (16), 5098, 2016.

39. YANG S.X., LIAO B., LI J.T., GUO T., SHU W.S. Acidification, heavy metal mobility and nutrient accumulation in the soil-plant system of a revegetated acid mine wasteland. Chemosphere, 80 (8), 852, 2010.

40. FU Y.H., HU Z.Q., XIAO W., RONG Y., LONG J.H. Subsidence Wetlands in Coal Mining Areas with High Water Level and Their Ecological Restoration. Wetland Science, 14 (5), 671, 2016.

41. HU Z.Q., LONG J.H., WANG X.J. Self-healing,natural restoration and artificial restoration of ecological environment for coal mining. Journal of China Coal Society, 39 (8), 1751, 2014.

42. ZAGAS T., TSITSONI T., GANATSAS P., TSAKALDIMI M., SKOTIDAKIS T., ZAGAS D. Land reclamation and ecological restoration in a marine area. International Journal of Environmental Research, 4 (4), 673, 2010. 
